\title{
Proceedings of the Society of British Neurological Surgeons: 69 th meeting
}

The 69th meeting of the Society was held in Aberdeen on May 22 and 23, 1964. The meetings were held in the University Medical Buildings, Aberdeen, and the President, Mr. G. F. Rowbotham, was in the Chair.

\section{SURGICAL TREATMENT OF CEREBRAL METASTASES}

MARTIN NICHOLS (Aberdeen) reported a series of 77 cerebral metastases treated over a five-year period. Fiftynine were from bronchus, five each from breast and naevo-carcinoma, two from kidney, one each from caecum, stomach, thyroid, ovary, and cervix. Seven patients lived more than a year but the average survival was 16 weeks overall and 13 weeks in bronchogenic lesions. Over a half of the cases were suspected as secondary deposits before operation. Earlier diagnosis of a secondary could usually be made in posterior fossa lesions and in these nine of 11 cases were only identified on histology whereas 36 of 54 cases of cerebral metastases were so identified.

In five cases no operation was carried out. In only one case was biopsy alone done and he considered this a dangerous procedure for many such patients died quickly from cerebral oedema. Close association with his thoracic surgical colleagues had enabled a diagnosis of primary site to be made in 29 cases whereas a diagnosis from the secondary was made in 30 cases. In 16 cases lobectomy or pneumonectomy had been carried out an average of 10 months before the cerebral operation. In secondaries recognized at cerebral operation 11 were referred to thoracic surgeons and six had a tumour removed, surviving an average of nine months; four were inoperable and survived an average of six-and-a-half months. $\mathrm{He}$ had the impression that $x$-ray therapy in these cases was better than he had expected and that a combination of radiotherapy and cytotoxic drugs might have an effect on slowing malignant growth greater than the sum of their individual effects. In the remaining group half the primaries were only diagnosed when the secondary was revealed at cerebral operation.

He concluded that the primary purpose of this type of surgery was to relieve symptoms and to improve the patient's condition in the time remaining to him and this had been successful. In particular, the relief of intracranial hypertension was important.

CLINICAL AND ANGIOGRAPHIC FINDINGS IN CEREBROVASCULAR INSUFFICIENCY

R. J. A. FRASER (Aberdeen) surveyed the clinical and angiographic findings in a series of 71 patients with premonitory or established signs of a stroke where it was considered that the underlying cause was cerebrovascular insufficiency in the territory of the internal carotid arteries. The presence and extent of atheromatous lesions was assessed by angiography, and bilateral angiograms, including localized views of the carotid bifurcation in two planes, were carried out in almost all patients. The atheromatous lesions were segmental, usually being at or near the internal carotid origin, but also quite commonly in the carotid syphon and sometimes in the middle cerebral artery. Lesions were sometimes present in more than one site and often bilaterally, especially in older patients.

The 71 cases were seen over a period of one year and were thought to represent a fair sample of the regional population. Thirty were females and 41 males. Most were between 50 and 60 years old, most being in the seventh decade. Over half of them had E.C.G. evidence of cardiac ischaemia and nearly $65 \%$ had an elevated blood pressure and in some the pressure was very labile.

Sixty of these patients were found to have atheroma. Eighteen of these had had premonitory symptoms only, 20 had premonitory symptoms followed by a stroke, and the remainder had had a stroke of sudden onset. Atheroma was present at the internal carotid origin in 54 on one or both sides. It was confined to the syphon in two, but 21 had syphon atheroma combined with atheroma at other sites. It was assumed that atheroma was the underlying cause of carotid thrombosis though trauma could have been a factor in two cases and was considered the cause in a third case which was excluded from the series.

It was considered that in 51 cases atheroma had been the cause of the stroke. Atheroma without narrowing was not considered causal although it was possible that emboli from such a lesion could give rise to stroke or premonitory symptoms.

In those cases without atheroma embolism and haemorrhage was considered the cause in two, and malignant hypertension in one. Injury was the cause in one child and acute angled kinking of the carotid was present in three cases. Four patients with no established aetiology were all in the younger age group.

No cases of carotid occlusion were found in the group with premonitory symptoms only and most of the unexplained cases were in this group. The extent of atheromatous disease was similar in the other two groups.

Fourteen operations were carried out and in 13 it was possible to clear the stenotic lesion. Several operations 
were carried out on stenotic lesions on the side opposite to the stroke and in cases of carotid occlusion on the opposite carotid if stenosed, in an attempt to improve the collateral circulation.

He concluded that the stroke syndrome is in many cases associated with atheromatous disease of the internal carotid artery and sometimes the middle cerebral. Cerebral embolism was not easy to eliminate as a cause in patients with heart disease and it should be appreciated that emboli might arise from the atheromatous lesions. Surgery might benefit some of these patients by increasing blood flow through the vessel and removing thrombus and possible sources of emboli.

\section{ASSESSMENT OF RADIOLOGICAL EVIDENCE}

R. A. MCKAIL (Aberdeen) demonstrated the radiological appearances of a number of cases of neurosurgical interest. He said that sometimes an abnormality remained unexplained though investigations showed it to be unrelated to the main disease. It was wise to remember these for future occasions. On other occasions odd and anomalous features might give the key to a diagnostic puzzle and sometimes neurological disease might be discovered during routine investigations for quite another purpose.

One case which had been hard to diagnose showed filling defects at either end of the third ventricle and this turned out to be a teratoma of the pineal with secondary spread to the hypothalamus and pituitary. In another case, a woman of 67 with neurofibromatosis and cavernous sinus syndrome from a carotid aneurysm, symmetrical soft tissue shadows were seen on either side of the nasopharyngeal air space. The condition remained undiagnosed until some years later similar appearances were noted in a man of 41 with pain and numbness in the right hand. The nasopharynx was explored under anaesthesia and the swellings found to be enlarged but benign Eustachian cushions. A third case had been associated with a pituitary tumour and, had the appearances not been recognized, might have been mistaken for a pharyngeal extension of this tumour. The condition was not rare and often associated with enlarged adenoids. A further case was described in which a cellular, and probably sarcomatous neurofibroma arising in the upper cervical region, had extended to the side of the neck giving rise to a soft tissue shadow in the nasopharyngeal air space as well as evidence of invasion of the posterior fossa and superior orbital fissure.

He then demonstrated three cases in which radiographs showed enlargement of the foramen ovale. The first case was a straightforward nasopharyngeal carcinoma. The appearances in the second case were very similar but no evidence of tumour was ever found and he concluded that this was a normal variant. In the third case, a woman of 33 presented with unilateral deafness, relieved by inflation of the Eustachian tube. There was enlargement of the foramen ovale and in view of the absence of clinical signs no further investigations were undertaken. Eighteen months later she returned with clear clinical evidence of a nasopharyngeal carcinoma. The foramen ovale had not changed in size but there was now evidence of erosion of the petrous apex.

SURGICAL TREATMENT OF SPINAL ARTERINOVEOUS MALFORMATIONS

A. R. TAYLOR (Belfast) described the surgical treatment of six cases of spinal angioma.

In the first two cases the angioma was removed. The lesion lay on the back of the cord, and the vessels, for the most part, did not appear to be intimately associated $\overrightarrow{\vec{F}}$ with the cord. They were iifted up and branches entering the cord were clipped; no coagulation was used. At the end of the operation the cords appeared to have been deprived of some of their normal vasculature as well as $\frac{\bar{F}}{D}$ the angioma and looked paler than normal. In both cases $\mathbb{D}$ there was an immediate and considerable improvement in motor function. There was, however, considerable ${ }^{\infty}$ posterior column dysfunction resulting from the opera- $\overrightarrow{0}$ tion which detracted a good deal from the good motor result. It was for this reason that he had sought for $\vec{\omega}$ a method of operation which was effective but less radical.

In the third case an extensive angioma from T.6 to L. 1 ? was exposed. The lesion extended over the whole of the $V$ back of the cord and consisted of longitudinally disposed or vessels joining each other at different levels, with wideg or spread varicosities. There was extensive arachnoidi and numerous small pockets containing the previous injected contrast solution and yellow cerebrospinal flui $\phi^{.}$. A needle was placed in two or three vessels about the middle of the lesion and pressure recorded on a simp $\mathbb{D}$ apparatus. This varied from 68 to $72 \mathrm{~mm}$./ Hg, was uß changed by compression of the vessel below but fell 10 to $15 \mathrm{~mm}$./ $\mathrm{Hg}$ on compression above. Clips wege placed along the vessels; there appeared to be only ome $\vec{c}$ large arterial vessel feeding the lesion and when this was clipped the whole lesion remained blue and desaturated. Loops of vessel which appeared to be occupying space and possibly compressing the cord were removed.

His experience in the subsequent three cases was similar. In each case the lesion lay along the posterior aspect of the cord, it appeared to have a single artery of supply, and, presumably, a single arteriovenous shunt. The blood $\mathrm{a}$ flow was unidirectional and the feeding vessel and flow $\overrightarrow{\bar{O}}$ direction could be determined by temporary compres- 3 sion of the vessels. This vessel was clipped and portions of the lesion which were clearly extramedullary were removed. Vessels closely applied to the cord or invested by pia were not touched.

Four of the patients had severely disabling symptoms? of four to seven years' duration. One died after mitral valvotomy but the other three had made some improvement after operation. One patient with less severe symp- $\bigcirc$ toms of two years' duration had improved to an almost normal status. One patient, the first operation, had pro-o gressed from normality to almost complete paraplegia in three months. After operation she had made an almost $\frac{7}{0}$ complete motor recovery over 18 months but remained severely disabled from posterior column loss resulting $\mathrm{N}$ from the radical removal of the angioma. 
He concluded that in many of these lesions the supply was from a single vessel and the blood flow unidirectional. If this were occluded and that part of the lesion compressing the cord removed, results were encouraging in patients not already severely damaged or in whom the damage had been present for a short time only.

\section{CAROTICO-CAVERNOUS ANEURYSMS}

H. H. Gossman (Sunderland) presented three unusual cases of carotico-cavernous fistula, one spontaneous and two traumatic, which had been taken from a series of 36 cases in Newcastle.

The spontaneous case was a woman of 76 first seen 10 days after sudden severe pain behind the left eye and a roaring noise in the left ear. There was left proptosis with pulsation and a complete ophthalmoplegia. An intracranial murmur was abolished by left common carotid compression. The left common carotid artery was ligated but the rapid development of contralateral weakness necessitated the removal of the ligature after 10 minutes. No further surgical treatment was undertaken. Five-and-ahalf weeks later it was noted that the murmur had stopped and two weeks later there was no murmur, no proptosis, or pulsation on the left but she had become blind in both eyes and there was a bilateral ophthalmoplegia. Two-and-a-half months after the onset she died of staphylococcal pneumonia. At necropsy there was an aneurysm of the left internal carotid which had ruptured and there was a clot at the point of rupture. There was thrombosis of both cavernous sinuses and the intercavernous sinuses. It seems that the spontaneous cure of the fistula had been achieved at the expense of bilateral cavernous sinus thrombosis, blindness, and ophthalmoplegia.

The second case was a man of 29 who sustained direct trauma to the left orbit and fronto-malar complex. Diplopia and a murmur had been noted by him from an early stage of his injury. Two-and-a-half months later there was a bilateral sixth nerve palsy, pulsating exophthalmos on the right with papilloedema, and haemorrhage and pallor of the left optic disc. A murmur was audible in the right malar region which was abolished by left common carotid compression. The left common carotid artery was ligated and the murmur was markedly diminished. A year and eight months later there was only $2 \mathrm{~mm}$. proptosis on the right, vision was $6 / 6$ in each eye and external ocular movements full. There was no intracranial bruit. In this case it appeared that thrombosis of the left orbital veins had occurred as a result of trauma and in view of this the carotid-cavernous fistula on the left, demonstrated by angiography, could not communicate itself to the orbital veins on that side but did so via the intercavernous and right cavernous sinus to the right orbital veins.

The third case was that of a man of 19 who sustained a scooter accident with right-sided otorrhoea and temporal bone fracture. A month later he complained of rightsided bruit. Five months later mild left proptosis developed and there was a bruit in the left temple abolished by left carotid compression. The diagnosis of left cavernous-carotid fistula was confirmed by angiography and the left common carotid artery ligated. The murmur was only abolished for about half an hour and a year later was still present and a bruit and thrill had developed at the site of the neck operation. At a further operation the common carotid artery was again ligated distal to the first ligature, the left external carotid was ligated above its superior thyroid branch, and the internal carotid was ligated in two places. The murmur was diminished but not abolished. Two years later there was still a bruit present on the left and also now audible on the right. Angiograms showed that there had developed at the site of the ligature a collateral circulation just below the level of carotid bifurcation which allowed blood to pass up the internal carotid in full force. At a further operation it was found that the superior thyroid branch of the external carotid was much enlarged and blood was coursing along it into the carotid bifurcation and up the internal carotid. The collateral circulation around the previous ligatures on the common carotid was also seen. The common carotid artery together with the collateral circulation was excised and the superior thyroid and internal carotid arteries ligated.

The histological changes in the excised carotid artery and the collateral circulation which had developed were demonstrated.

\section{CAROTID-CAVERNOUS ARTERIOVENOUS FISTULA}

NORMAN DOTT (Edinburgh) discussed carotid-cavernous fistulas and said that he was surprised that there was a feeling that treatment of the unilateral case at least still presented a problem. He felt that the newer treatment suggested by Walsh of liberating a free muscle embolus into an unligatured carotid artery was so.ncwhat risky and uncertain.

He noted that the spontaneous variety developed when an intracavernous carotid aneurysm ruptured into the enveloping venous sinus. It might have been quite silent before this event or have occasioned ocular palsies and trigeminal involvement. It was commoner in females and they often ruptured during the latter part of pregnancy. There was often no precipitating cause of rupture.

The traumatic variety might become apparent immediately or its advent be delayed for a week or more. It would seem probable that a fracture of the sphenoid must always occur and inflict damage on the arterial wall though it was seldom possible to demonstrate this. $\mathrm{He}$ felt that the surviving cases were probably those with a good anastomotic circulation in the circle of Willis; were this not present the drain of blood from the carotid might well prove fatal or provoke massive cerebral infarction.

Venous dilatation in the unsupported orbital veins occasioned progressive proptosis, oedema, and chemosis and the cornea might become endangered by exposure and malnutrition. It was often these progressive ocular events which demanded urgent treatment. In other cases it was the bruit which demanded treatment. More rarely a cerebral vein close to the cavernous sinus might rupture under the stress of arterial pressure and the case present as an intracranial haemorrhage. 
He then reviewed the various forms of treatment used over the past 40 years. Common carotid ligation had been advocated first and, though this might cure a few mild cases, it was a dangerous operation carrying a high risk of hemiplegia and he felt it should be abandoned. He had next used simultaneous ligation of the internal carotid in the neck and intracranially below the posterior communicating artery. This had been more successful but was not invariably so and was subject to occasional ocular complications. The ophthalmic artery was not excluded from the fistula nor were three small branches of the internal carotid within its osseous canal. In some cases, therefore, there might be ophthalmomalacia and loss of vision following ligation. To overcome this complication he then added intracranial ligation of the ophthalmic artery but exposure in this area might be difficult and not without surgical risk to the optic nerve. Even when this was done there still remained the intracanalicular branches of the carotid artery feeding the fistula.

His present practice was to perform the double ligation of the carotid and then open the supraclinoid segment below the occluding clip and stuff the artery with small strips of muscle. The artery was then closed by securing a previously placed small tape garter around it. The muscle induced thrombosis and occluded the mouths of the ophthalmic artery, other smaller branches, and the fistula itself. He felt that this treatment had solved the problem of a reliable and safe treatment for unilateral carotidcavernous fistula. It was safe both for the brain and the eye and recurrence would seem impossible.

\section{SOME HAEMODYNAMIC EFFECTS OF CAROTID ARTERY CLAMPS}

J. BRICE, D. DOWSETT, and R. LOWE (London) said that they had investigated the effects of adjustable artery clamps on blood flow, mean pressure, and pulse pressure in the common carotid artery. The Preston clamp was used and measurements made in 25 patients. They measured flow through the artery and pressure, above and below the clamp, using an electromagnetic flowmeter and intra-arterial pressure needles. From a knowledge of the exact point of complete occlusion and the mechanical characteristics of the clamp they were able to measure the combined wall thickness of the artery and thereby deduce the slit size and cross-sectional area of the vessel at various stages of occlusion. These findings were confirmed on casts of cadaver arteries.

They found that no change took place in pressure or flow until the arterial lumen was almost completely occluded and the slit size about $0.5 \mathrm{~mm}$. This dimension had been quite constant in all patients despite wide variations of initial arterial size. The change in mean pressure, pulse pressure and flow occurred simultaneously and at no point could the distal pressure be reduced without altering flow. The changes in pressure and flow occurred rapidly over a very small range of adjustment of the clamp. They stressed, therefore, that an efficient clamp must be capable of very fine adjustment and should have no mechanical 'backlash'.

They also found from repeated measurements of wall thickness after clamping that changes took place. In three patients the walls thickened after clamping, prob- ably from damage to the wall and oedema. In 11 cases the wall thinned by amounts varying from 0.1 to $0.7 \mathrm{mr}$. This was measurable as soon as $\mathbf{1 0}$ minutes after clampirg and as long as eight days afterwards. The rate of thinnirf was variable. Histology showed that the thinning too place in the adventitia and they felt this was probably d\&e to extracellular fluid being massaged out of the arteri wall by the effect of pulsation against the rigid clamp walls.

They concluded that because of the extremely sma्l dimension for an effective narrowing of an artery an because of changes that take place in the wall of any artery within a rigid clamp, it was not possible to produce a gradual and progressive reduction in pressure and flow This had been confirmed by ophthalmodynamometr. All that probably resulted was a postponement of effective ligation for several days or at the most an intermitterfif reduction in pressure and flow. They did not think tha minor adjustments in clamp design would solve this problem.

TOTAL CEREBRAL ANGIOGRAPHY IN SPONTANEOUS INTRACRANIAL HAEMORRHAGE

A. A. DONALDSON (Edinburgh) reported a series of 5 cases in which total cerebral angiography had bee⿳⺈ carried out in the investigation of spontaneous intrav cranial haemorrhage. Twenty-seven were carried out bं femoral catheterization and 19 by axillary. The latwes? route was preferred as a shorter catheter could be usied which allowed a more rapid injection of contrast mediming In four cases the brachial artery was exposed and a winebore (14 gauge) cannula inserted. This produced excel[ent filling of the right carotid and vertebral circulations $\$$ in $10 \%$ of cases the left side also. It had been repogeg that compression of the carotid raised the percentageof left-sided filling to 50 . In two cases the right carotid mas injected with the intrathoracic pressure raised to obstrurct venous return to the heart. This produced excellent filling of the intracranial vessels but a drop in blood pressure occurred, though for a short period only, and this made if unsafe for routine use. One of their patients had diec after the procedure with widespread infarction of the cerebral hemispheres.

The new less viscous sodium metrizoate (Triosil) haळ్ been used routinely in 60 or $75 \%$ concentration, 30 to $4 Q$ $\mathrm{ml}$. being injected for each series of films. Posterior $\overrightarrow{\vec{D}}$ lateral, and axial views were usually taken though oblique views could be helpful and stereoscopic lateraF views were advisable. When appearances were in doubt? supplementary carotid or vertebral injections were car ried out. Apart from the one case mentioned no patien? had shown any deterioration attributable to the methodP nor had any serious circulatory impairment in the limbs been noted.

Nine post-operative control examinations were carried out. No further aneurysms were found. The remaining cases were all primary examinations. Thirteen gaveo positive findings and in three of these supplementary injections were necessary. All were followed by operatives treatment which confirmed the $x$-ray findings.

The remainder were negative findings and less than half had supplementary injections which confirmed this:" 
Most were minor bleeds without focal signs and in a short follow-up of less than a year only one recurrent haemorrhage had been reported.

Re-examination of the films in this patient showed an anterior communicating aneurysm which had been missed.

UNUSUAL BEHAVIOUR OF A CEREBELLO-PONTINE ANGLE TUMOUR

P. V. BEST (Aberdeen) reported unusual behaviour in an acoustic neurinoma. The patient, a woman of 46 , first presented four years previously with deafness and hissing in the left ear of 10 years' duration and discomfort in the ear for one month. A firm polypoid mass filling the left external auditory meatus was removed with a snare and was thought to arise from the promontory through a large perforation in the drum.

Four years later occipital headache spreading to the left eye and blurring of vision brought her to hospital again. There was bilateral papilloedema, left facial weakness, conduction deafness and moderate nerve deafness on the left but no sensory changes in the face or cerebellar signs. There was a recurrent mass in the left external meatus. Radiographs showed a sharply defined area of bone destruction in the left petrous bone involving the internal meatus and appearing to extend through to the base in the region of the jugular fossa. Myodil ventriculography confirmed the presence of a left posterior fossa mass and exploration was carried out. This revealed a tumour like an acoustic neurinoma in the angle and an intracapsular removal was carried out. After an initial good recovery she developed sudden respiratory and cardiac arrest and died.

Post-mortem examination showed a marked foraminal pressure cone. The remaining capsule of the tumour was present in the left angle and there was mild symmetrical hydrocephalus. Sectioning of the temporal bone showed that the tumour filled the middle ear cavity, the mastoid air cells, the medial part of the external meatus, and extended downwards to the region of the jugular fossa. Small tumour nodules projected through the tegmen tympani under the dura of the middle fossa.

The tumour removed four years previously had been considered a sclerosing haemangioma but the histological appearances of this tumour, that removed at the second operation, and the post-mortem material were identical and were those of an acoustic neurinoma with compact and loose (Antoni A and B) components. An additional post-mortem finding had been a small squamous carcinoma in the lower lobe of the left lung.

CLINICAL USE OF LOCAL CEREBRAL HYPOTHERMIA WITH CIRCULATORY ARREST

BERNARD WILLIAMS (Birmingham) described the method developed in Birmingham to provide local cerebral cooling and local circulatory arrest. It had been adapted from the method of Kristiansen and preliminary experimental work on dogs had suggested certain principles which would afford maximum safety. Whole blood should not be used to prime the apparatus or replace blood loss until the cooling was ended. Low molecular weight Dextran was used to lower viscosity and prevent sludging. Carbon dioxide should not be lowered by hyperventilation and spontaneous respiration should be used as this served as a monitor of medullary function. Halothane anaesthesia prevented the vasospastic response to cold blood and rapid cooling should be avoided to lessen this response. For this purpose an inefficient disposable P.V.C. heat exchanger coil had been developed. A constant pressure perfusion was preferable to a preset rate and for this purpose a modification of the bubble trap of Kristiansen had been used.

$\mathrm{He}$ then described the operative procedure in man. The patients had been wrapped in heat exchanger blankets and surface cooling was used to reduce the rectal temperatire to $34^{\circ} \mathrm{C}$. which covered the period of carotid cannulation and thereafter rewarming counteracted the effect of cold blood returning to the heart. The E.C.G. was recorded and thermocouples attached in the temporal regions, brain surface, oesophagus, and rectum. On the opposite side to the craniotomy the inferior thyroid and vertebral arteries were snared together with $\frac{1}{8}$ in. nylon tape; the common carotid was snared separately. On the ipsilateral side the common carotid was exposed and the superior thyroid ligated. The vertebral and inferior thyroid were snared separately.

After receiving $3 \mathrm{mg}$. heparin per $\mathrm{kg}$. a cannula was passed into the jugular vein towards the heart and the common carotid was cannulated proximally. Blood was then used to prime the apparatus whilst the rheomacrodex from the circuit was returned to the heart. During mixing the distal common carotid was cannulated and perfusion with cold blood started with a pressure slightly above the mean systemic pressure.

As the temperature of the ipsilateral hemisphere fell there was some cooling of the contralateral hemisphere and posterior brain; this cooling was improved by clamping the opposite common carotid about 10 minutes later. After a further 10 minutes one of the vertebrals was clamped. At this stage, because of the difficulty in determining that the posterior communicating arteries were adequate, the perfusion was stopped and a small cortical artery divided. If the bleeding from this was brisk the other vertebral was occluded and the perfusion continued through one artery, nourishing the whole head with its diminished metabolic demands. Shortly after this respirations stopped and the blood pressure started to fall. Respirations were assisted and the perfusion stopped. At this stage, vascular lesions could be approached with confidence and a ruptured aneurysm would only ooze blood. In this state the patients were fairly stable with brain temperatures from about $8^{\circ} \mathrm{C}$. in the perfused hemisphere to $20^{\circ} \mathrm{C}$. elsewhere, a cone temperature of 28 to $30^{\circ} \mathrm{C}$. and a mean systemic pressure of 30 to $50 \mathrm{~mm}$. Hg. When elective surgery was completed the snares were all removed and the arteriotomies repaired. Re-warming was usually passive so that heparin could be neutralized immediately; in some cases arterial-venous re-warming was used. Wounds were closed with drainage, continuous suction being used beneath the scalp flap.

This technique had been used in seven patients. Three patients with aneurysms and one with a glioma made excellent recoveries. One patient with a middle cerebral 
aneurysm who was moribund died three weeks later unchanged by operation, one with glioma died on the second day with no evidence to incriminate the perfusion, and one patient with glioma, the first operation, died 18 hours after operation. An accidental undiagnosed low blood pressure contributed to death.

\section{EFFECTS OF ANAESTHESIA ON INTRACRANIAL PRESSURE}

W. B. JENNETT and D. GORDON MCDOWALL (Glasgow) discussed the role played by various anaesthetic measures in reducing intracranial tension. They noted that various centres had adopted different combinations of controlled respiration, hyperventilation, hypertonic solutions, hypothermia, and hypotension and had considered halothane as an anaesthetic particularly suited to neurosurgery. Because these developments had been almost simultaneous and were seldom used singly it was difficult to know what benefits should be ascribed to each, and what their separate risks might be.

They then described the results of studies of cerebral blood flow which had been made with Dr. A. M. Harper and Dr. I. Jacobson using the Krypton 85 technique of Lassen and Ingvar. This work had shown that light halothane anaesthesia reduced both the blood flow and oxygen consumptions of the cerebral cortex of the dog by approximately $50 \%$. Since flow and oxygen requirements were equally reduced, cerebral oxygenation, as indicated by the oxygen saturation in the superior longitudinal sinus, was not impaired. A previous study by Dr. Harper in quantitating the effects of changes in arterial carbon dioxide tension on blood flow through the cerebral cortex was mentioned and the results were discussed with reference to the use of hyperventilation techniques in anaesthesia. An account of cerebral blood flow measurements in man by the Xenon clearance technique of Glass and Harper was given.

They pointed out that the amount of blood in the intracranial vessels was the only thing which could change rapidly so that a chart of rapidly changing intracranial pressure could be taken as reflecting changes in blood volume, but not of course, blood flow. Intracranial pressure had been measured in the cisterna magna of dogs and the lateral ventricle or lumbar theca of man, together with central venous pressure in the inferior vena cava in dogs and the superior vena cava in man. All observations were made under controlled respiration at fixed ventilation and arterial or capillary $\mathrm{pCO}_{2}$ and $\mathrm{pH}$ was also monitored. They confirmed that the introduction of halothane anaesthesia resulted in a rise of intracranial pressure but no change in central venous pressure. There was compensation after a period of time but withdrawal of halothane resulted in a fall of intracranial pressure to lower levels than before. Re-introduction of halothane later produced less effect. When intracranial pressure was already low from hyperventilation or hypothermia, halothane only produced a small rise of pressure though a considerable rise could still be produced by the inhalation of $\mathrm{CO}_{2}$.

\section{MANAGEMENT OF CHORDOMATA}

J. F. SHAW (Edinburgh) reviewed a series of 21 chordo- mata treated in the period 1941-63. Thirteen of these were $\frac{\text { o }}{Z}$ in the sacro-coccygeal region. The usual form of presenta- $\mathbb{D}$ tion was by sacral pain and nerve root involvement ac- $\bar{T}$ companied by a palpable tumour per rectum and osteo- $\leftrightarrow$ lytic sacral lesion on radiography. He stressed that this was the only group amenable to radical excision. The sacrum below its second piece was excised taking carew to preserve the third sacral nerve. The pelvic floor could $\hat{\sigma}$ be repaired with nylon mesh and sump drainage to con- $\overline{\frac{D}{2}}$ trol accumulation of serous fluid in the large dead space was useful. He felt that the results of this operation were : better than a lesser procedure and it had been carried out in six of the cases. He had no evidence that radiotherapy was of value in this group. He stressed that the sacralc tumours belied their reputation for benignity and four cases in this series had metastases, though all had had? some form of operation and primary removal might be@ the safer procedure. In inoperable cases palliative pro-0 cedures such as anterolateral cordotomy for pain or the excision of painful deposits both local and metastatic $\overrightarrow{0}$ might be needed.

Tumours of the clivus were six in number of which onew was an incidental post-mortem finding. Headache, cranial nerve palsies, and destruction of the clivus were? the usual clinical findings. He felt that in this group? prognosis was governed by the rate and direction of growth rather than the treatment carried out. In those confined to the posterior fossa, biopsy and diversion $\not f\}$ cerobrospinal fluid only should be done, whilst in those expanding upwards or forwards diversion of cerebrospixif fluid and subtotal removal should be done. Deep $x$ therapy should be given though its worth had not beeng proven.

Two cases were in the cervical spine and he stressed thats excision followed by radiotherapy was the treatment choice. Fusion of the spine would often be needed. Injese tion of the trigeminal nerve and section of the nin $\overrightarrow{7} \vec{r}$ tenth, and upper cervical nerves could give good reliefo of pain in the inoperable cases.

He concluded that these tumours, although reputedly benign and slowly growing, demanded some form of treatment and only one had been an incidental post $\frac{\partial}{0}$ mortem finding. Early recognition and treatment should be possible.

OBSERVATIONS ON THE RADIOLOGICAL DIAGNOSIS AND? TREATMENT OF THE DANDY-WALKER MALFORMATION

G. MORELlo, F. MIGliaVACCA, and M. BIANCHI (Milan) reported their experience in eight cases of the Dandy Walker syndrome. These had occurred in the period since 1946 and they noted that the condition was probi ably more common than had previously been supposed 3 There were six males and two females. Four werb children (1-6 years) and four adults (29-37 years). In the children enlargement of the head, mental retardation, unsteadiness in walking, and a cerebellar syndrome were common features. Two had papilloedema. Raised intra cranial pressure of two to 20 months' duration witK papilloedema and cerebellar signs occurred in the adul patients.

The posterior fossa was explored and the findings wera 
very similar in seven cases. There was wide separation of the cerebellar hemispheres by a large cyst formed by the enlarged fourth ventricle; the vermis was rudimentary. In one case the fourth ventricle was more enlarged on one side and in another there was aplasia of the tentorium.

They felt that in radiological diagnosis too much importance had been attached to the high position of the impression of the transverse sinuses. They stressed that these impressions could not be detected in radiographs with certainty until the fourth year of life and this sign was missing in all their four children. In addition there were some proven cases in which the sinuses were in the normal position and in three of their four adult cases this was so. They also felt that other signs such as enlargement of the head, wide posterior fossa, and diastasis of the lambdoid suture were only commonly present in children and in the adult cases, as in their series, the skull developed normally in shape and size.

They also stressed that in ventriculography the enlarged fourth ventricle might not be filled. This was probably due to the atrophied vermis acting as a valve and blocking the aqueduct when the lateral ventricular pressure was lowered.

In discussing treatment they noted that in their series and in cases from the literature, the results of removing the thin posterior wall of the cyst were not satisfactory. The mortality was high and good end-results were obtained in less than half the cases. They presumed that this was due to failure of absorption of cerebrospinal fluid due to malformation of the subarachnoid spaces.

They felt, therefore, that a better form of treatment must be sought and in their last case no posterior fossa exploration had been carried out but a ventriculo-venous shunt with a Spitz-Holter valve had been undertaken. The case had been followed for only three months but the result appeared to be satisfactory.

AN UNUSUAL CASE OF THE DANDY-WALKER SYNDROME

N. O. A MELI (Teheran) reported that he had treated four cases of this syndrome in children aged 5-15 years. He now reported on one of them as it might throw some light on the pathogenesis of this condition. The child, aged 8 years, was admitted for ataxia, headaches, and vomiting. He had had a large head from age of 8 months and had been mildly mentally retarded. Examination showed him to be mentally dull, to have a large head, papilloedema, bilateral sixth nerve paresis, and bilateral cerebellar signs, worse on the left side. Radiographs showed a large skull with wide posterior fossa and high impressions for the lateral sinuses. There was also platybasia and KlippelFeil syndrome. Ventriculography demonstrated the greatly enlarged fourth ventricle. At posterior fossa exploration a single cyst was found. This extended down to the level of the axis and the wall was then reflected up onto the floor of the fourth ventricle. Two small spherical masses were seen on either side of the large fourth ventricle and there was a large and short aqueduct of Sylvius connecting with the third ventricle. There was no indication of a central canal opening at the obex, this area being covered by the extension of the cyst wall. The cyst wall was removed. It had been ascertained that the cyst contents was normal cerebrospinal fluid. The cyst wall consisted of neurological tissue covered with one layer of ependymal cells.

He then reviewed the various theories held to account for this condition and stated that he believed it was due to arrest of development of the area of the fourth ventricle between the sixth and twelfth weeks of foetal life. This would explain most of the features encountered in these cases, including associated anomalies such as platybasia and the Klippel-Feil syndrome. These could not be explained solely on a basis of atresia of the foramina of the fourth ventricle.

$\mathrm{He}$ also reported a case of traumatic extradural haemorrhage from an aneurysm of the middle meningeal artery.

\section{DIASTEMATOMYELIA}

L. P. Lassman and C. C. michael James (Newcastle) presented a series of 24 cases of diastematomyelia in 60 consecutive operations on children with spina bifida occulta. They said that this was an intrinsic abnormality of the cord, and not treatable as such, but that the bifid cord could function normally. It was commonly, but not always, associated with extrinsic abnormalities of embryological origin which were the cause of neurological changes affecting the lower limbs, bladder and bowel. These extrinsic abnormalities were surgically treatable.

Analysis of the symptoms and signs had shown that diastematomyelia could not be diagnosed on clinical grounds alone. A bone septum was occasionally evident on radiographs and the condition could be demonstrated by myelography. The only certain means of making the diagnosis was by an exploratory laminectomy.

Ot the 24 cases, 13 had a separate dural sheath for each spinal cord with an osseous, fibro-cartilaginous or fibrous septum between the sheaths. Eleven cases had a single dural sheath enclosing both spinal cords, none of them had a septum between and, except in one case, there were associated aberrant tissues causing either pressure or traction on the spinal cords. The single exception had diastematomyelia in the thoracic spine which was clearly not the cause of the clinical changes; there was a further area of diastematomyelia in the lumbo-sacral region diagnosed by myelography but as yet unexplored surgically.

Surgical treatment consisted of the removal of a septum if it were present, together with the intermediate dura and the division of any aberrant non-functioning tissues so that the spinal cord was no longer affected by local pressure nor prevented from ascending within the vertebral canal as the child grew.

PROGNOSTIC FACTORS IN THE TREATMENT OF PARKINSONISM BY STEREOTACTIC SURGERY

B. H. DAWSON (Salford) discussed the factors influencing prognosis in the surgical treatment of Parkinsonism. He said that surgery was directed at a set of symptoms rather than a disease entity and the disability caused by them varied from case to case and from time to time in the same patient. It was not-unexpected, therefore, that relief 
from surgery was a little uncertain both as to degree and nature. In some, symptoms totally relieved after operation might return in full force after a variable time whilst in others symptomatic relief only appeared some time after operation. It was very difficult to assess surgical results which were contaminated by medication and the placebo effect of an operation. He felt that of all factors influencing the result the pre-operative clinical pattern of the patient exerted the greatest effect.

He reported on a series of 77 operations (six repeat, 11 bilateral) in 60 patients. The technique was reasonably uniform, using the Leksell machine and making a radiofrequency lesion in the ventrolateral thalamus. To measure disability a system of pre- and post-operative scoring was used, based on that introduced by Schwab, supplemented by interviews with the patient and relatives before and after operation.

The clinical results were divided into three groups. In the first group the results were considered to be excellent. The patients' overall capabilities after operation were so changed as to give them a completely new and improved type of existence. They might be able to return to work after a long period of unemployment or released from being bedfast or chairbound to an independent existence. There were 12 patients in this category with an average age of 54. None of these patients had any mental symptoms before operation and all had a very high morale.

In group 2 the results were good. The patients had improvement in function and showed increased independence after operation without any adverse surgical complications. There were 22 patients in this group which included five bilateral operations.

Group 3 consisted of the poor results. These patients remained gravely disabled with their general state of dependence unchanged or had personality change or progressive mental deterioration which persisted or appeared after operation. There were 16 patients in this group with an average age of 55 . Six patients had a long history of depression before operation, including several suicidal attempts, and persisting low morale hindered effective rehabilitation. Three with poor intellectual function, although relieved of their physical symptoms, made no effective rehabilitation and one patient showed defective memory soon after operation and this process continued. Two developed the symptoms of chronotaraxis described by Spiegel and Wycis and were quite unable to assess the passage of time.

Ten of the 60 patients had died. One death was due to a fatal thalamic haemorrhage following operation and three died on the ward from pulmonary embolism. These three had all shown evidence before operation of circulatory insufficiency and their limbs were blue, cold, and ischaemic looking. Two further patients died of pulmonary embolism some months after returning home though they had been quite reasonable surgical results. One patient died of an atherosclerotic brain haemorrhage 16 months after operation and three died after returning home from progression of the disease.

$\mathrm{He}$ had found that muscular rigidity and dystonic contractures were usually relieved by surgery and provided a dramatic restoration of function in those patients without other general symptoms of Parkinsonism. Pain in

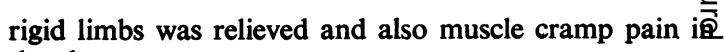
the chest.

Fine tremor and medium amplitude tremor associated with stress and anxiety were both relieved by surger though post-operative stress could still provoke attacks of tremor in some cases. Wide amplitude forceful tremô was difficult to relieve and continued to show undep stress.

In most patients speech difficulty was unaffected an $\underline{\underline{\Phi}}$. was sometimes worsened, usually from operations on the dominant hemisphere. Walking difficulties were not ofter. relieved by surgery unless the difficulty was due to: rigidity and dystonic contracture. Symptoms due t $\$$ involvement of the autonomic nervous system were seldor improved by surgery. He found, like other workers, tha和 patients with long-standing psychiatric symptoms wer not rehabilitated following surgery and pre-operativ $\Phi$ evidence of organic dementia was associated with poof surgical results.

He concluded that irrespective of the surgical techniques used certain symptoms were more resistant than others. and that the functional improvement, therefore, shown b⿸广 an individual depended upon his pre-operative symptoms. He stressed that in patients showing evidence of arteriat disease pulmonary embolism was a likely complicatior

DEPTH MICROELECTRODE RECORDING FOR PRECISIOAD STEREOTAXY

R. M. GAZE, F. J. GILlINGHAM, and S. KALYANARA (Edinburgh) reported on their method of microelectr囘e. depth recording in stereotactic surgery. They nofed that many attempts were being made to improve curacy of placement of lesions in intracerebral targets It was realized that radiological methods were by themselves sufficiently accurate because of the individual anatomical variation of the human brain Physiological methods like stimulation or reversib heating or cooling increased the accuracy but did not ensure $100 \%$ reliability. Their investigations had showg that there might exist an error of $\pm 5 \mathrm{~mm}$. in intracere bral targets in spite of radiological corrections.

The method they had used for the past two years was similar to that of Guiot and Albe-Fessard who use bipolar recording and had been able to differentiate be tween grey and white matter in deep intracerebral regions $\overrightarrow{3}$ They were using unipolar microelectrode recording to delineate accurately the various structures along the electrode track.

The electrode consisted of a $0.5 \mathrm{~mm}$. diam. tungsten wire sharpened electrolytically at the tip to a diameter of 20 to $30 \mu$; the shaft was insulated, except at the tip, with Bakelite lacquer. The electrode was carried in a $\mathrm{mm}$. diam. stainless steel tube which also formed the indifferent electrode. The electrode could be withdraw inside a small Teflon cuff in the end of the carrier tub or protruded $5 \mathrm{~mm}$. from the end. The electrode could bo advanced by a few microns at a time by the micrometer screw of the stereotactic apparatus. Recording was vide a cathode follower to pre-amplifier and thence to an: oscilloscope and audioamplifier. The stereotactic tech nique was that of Guiot, modified by Gillingham, and 
posterior track was used to reach the thalamus, internal capsule, and pallidum by a single electrode insertion.

The sensory relay nuclei of the thalamus gave consistently identifiable records. There was an increase of background activity and evoked responses could be obtained from stimulation of the appropriate part of the body. All responses were obtained from the face or upper limb. The face area appeared to be in front of, above and medial to the part receiving fibres from the upper limb. The multi-unit activity recorded from the thalamus and fast asynchronous spikes recorded from the pallidum contrasted sharply with the total lack of activity encountered in the internal capsule. As the electrode was advanced, therefore, the width of the internal capsule in the area traversed could be inferred. The mean width in 26 cases had been $8 \mathrm{~mm}$. They had used the method in 36 patients. In eight Parkinson patients purely capsular lesions had been made, after defining the position of the capsule by this recording technique. Effects on tremor and rigidity were quite satisfactory and comparable to thalamic and pallidal lesions. It was probable that the fasciculus lenticularis had been interrupted by these lesions. They felt that such capsular lesions were able to control oculogyric crises more effectively than thalamic or pallidal lesions. They stressed that audiomonitoring was essential in this method as the ear was able to identify the rhythms and changes in activity which were not easily seen on an oscilloscope. It was also important to keep the electrode tip withdrawn during forward movement of the carrier, otherwise small vessels might be damaged as had happened in one of their patients.

They stated that in view of the great accuracy of definition of intracerebral structures, lesions could now be made at any desired place in spite of individual anatomical variations between the brains of different patients. They believed it to be a precise, reliable and harmless method of intracerebral target localization which could be used not only for the thalamus, capsule and pallidum but also for any region where grey and white matter were adjacent to each other.

\section{SURGERY IN DISORDERS OF MOVEMENT OTHER THAN} PARKINSONISM

PETER GORTVAI (London) reported a series of 30 cases of dyskinesia other than Parkinsonism treated since 1959. A modified McCaul method was used and the lesions made in the thalamus by the injection of a paste of Etapolin and kaolin.

Seven cases of Huntingdon's chorea were treated; all were in the third to fifth decade and had a positive family history. Abnormal movements were the most prominent feature, dementia was mild and the psychosis often seen in this condition was usually absent or only slight. It was noted that electrical stimulation in the area of the lesion had an effect on the choreic movements in every successful case. Movements were either diminished in intensity or jerky movements reminiscent of chorea were induced. In those cases developing post-operative hemiparesis, stimulation either produced no result or a slight response of the capsular type. All cases had a facial weakness and there was severe limb paresis in two cases. All cases were improved to some degree but in three the improvement was marred by significant hemiparesis. In three cases definite improvement in movements ipsilateral to the lesion were noted.

It was found that those cases with the worst results and hemiparesis were those in whom atrophic ventricular enlargement was greatest. The site of the lesion had been determined by the lateral limit of the body of the lateral ventricle so that these cases had had lesions made further from the midline than the others. Investigation of the brains from cases of Huntingdon's chorea showed, however, that though the lateral ventricle might be widened there was no lateral displacement of the thalamus. He concluded, therefore, that lesions in the ventrolateral thalamus in these cases should be centred 16 to $17 \mathrm{~mm}$. from the midline whatever the size of the lateral ventricles. In two further cases this information was utilized and a lesions $17 \mathrm{~mm}$. from the midline produced a fair physiological result without hemiparesis.

Seven patients with disseminated sclerosis were operated on and he stated that such patients who had no or only slight dementia and were greatly disturbed by unsteadiness of the hands could be improved by thalamic lesions. Two cases had both sides treated with a sixmonth interval. In all cases, involuntary movements in the upper limb contralateral to the lesion were decreased. No effect was noted in the ipsilateral limbs. Weakness of voluntary movement was not increased and there was no further impairment of intellectual function. The dysarthria was increased somewhat in patients with bilateral operations. One patient, who was suffering from a rapidly advancing form of the disease, died a few months after operation. He concluded that operation should be performed in the quiescent stage of chronic disease.

In five cases of choreoathetosis slight improvement was obtained in only one case, and this at the cost of a slight hemiparesis. One patient was dysarthric after operation. In the other patients no change was noted in involuntary movements. He felt that the mechanism of involuntary movements in these cases was independent of that part of the thalamus connected with the motor system.

Four patients with infantile hemiparesis were treated. These were patients with unilateral weakness of voluntary movement, muscular rigidity and deformity, of unknown aetiology, commencing in early childhood and without involuntary movements. Deformity and muscular rigidity were favourably influenced by operation. Hemiparesis was caused in one patient who was already very severely disabled and demented.

Three cases of dystonia musculorum deformans were treated. Two were brother and sister in whom torsion spasm had started in one lower limb and spread to the other in one case. Thalamotomy produced great improvement on the side contralateral to operation and some on the ipsilateral side though the maximum benefit was not noted until six weeks after operation. In the third patient, a woman of 35 , operation alleviated movement on both sides and a further operation In the other side abolished all involuntary movements.

Two patients with hemiballismus were treated. The abnormal movements ceased immediately after operation 
though there was some return of abnormal movements in one case but by no means as severe as pre-operatively.

In one case of Hallervorden-Spatz disease, bilateral thalamotomy improved the violent abnormal movements and facilitated nursing. He died a few months later from progression of the disease.

One case of tremor of the right arm, thought to be caused by a lesion in the red nucleus, was completely relieved by thalamotomy.

He concluded that thalamotomy could offer relief of as varying degree in many conditions where abnormal movements or muscular rigidity caused disablement. Dystonia musculorum deformans reacted most favourably whilse choreoathetosis was not influenced by this operation.

\section{The October 1964 Issue}

\section{THE OCTOBER 1964 ISSUE CONTAINS THE FOLLOWING PAPERS}

Hereditary metabolic myopathy with paroxysmal myoglobinuria due to abnormal glycolysis L.-E. LARSSON, H. LINDERHOLM, R. MüLLER, T. RINGQVIST, and R. SÖRNAS

Fact and fallacy in measurement of conduction velocity in motor nerves JOHN A. SIMPSON

Analysis of electrical activity in healthy and dystrophic muscle in man R. G. WILLISON

Role of infection in the Guillain-Barré syndrome s. C. MELNICK and T. H. FLEWETT

Serum fatty acids in multiple sclerosis R. W. R. BAKER, R. H. S. THOMPSON, and K. J. ZILKHA

Leber's disease with symptoms resembling disseminated sclerosis F. LEES, A-M. E. MACDONALD, and J. W. ALDREN TURNER

Subdural empyema: A review of 29 cases EDWARD HITCHCOCK and ALEXANDER ANDREADIS

Recurrent subarachnoid haemorrhage from paraventricular lesions with normal angiography R. M. KALBAG
Death due to cerebral vasospasm R. M. BUCKLE G. DU BOULAY, and BARBARA SMITH

Primary choroid papillomas in the cerebello-pontine angle GIULIO MORELLO and FRANCO MIGLIAVACCA

Thoracic and lumbar intraspinal tumours associated why increased intracranial pressure FRANZ E. GLASAUER

Spinal cord compression in pseudohypoparathyroidi DEREK R. CULLEN and JOHN M. S. PEARCE

Clinical trial of methysergide and other preparationsân the management of migraine D. A. CURRAN and J. LANCE

Endoxana (cyclophosphamide) in the treatment $\stackrel{0}{\frac{2}{5}}$ intracerebral malignancy F. CLIFFORD ROSE, S. N. $^{+}$ BHAGWATI, and WYLIE MCKISSOCK

Location of pupillomotor and accommodation fibres in the oculomotor nerve: Experimental observations in paralytic mydriasis FREDERICK $W$. L. KERR and WEEMS HOLLOWELL

Book reviews

Copies are still available and may be obtained from the PUBLISHING MANAGER, BRITISH MEDICAL ASSOCIATION, TAVISTOCK SQUARE, W.C.I., price 18s. 6D. 